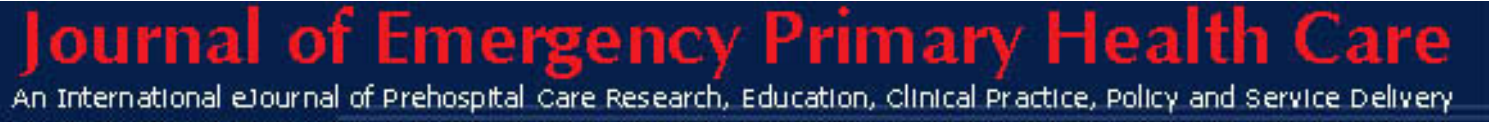

ISSN 1447-4999

\title{
Education
}

\section{"RESPONSE" - THE ORIGINS AND HISTORY OF THE INSTITUTE OF AMBULANCE OFFICERS' (AUSTRALIA) OFFICIAL MAGAZINE}

\author{
David Shugg and Les Hotchin
}

\section{Preamble}

The idea for a magazine published for ambulance officers by ambulance officers came from two forward thinking 'ambos' in country Victoria, about the same time as the Institute was formed.

The Victoria Division - at the time, arguably the most progressive (some would say aggressive) branch of the Institute (we held our inaugural meeting four months before the public launch of the Institute), assembled influential medical support for the project and provided seed funding to assist in the publication costs.

The Institute became the vehicle to push the magazine out around the nation, but it took a lot of pushing by a few people to keep the momentum up.

Parochialism, a problem on an intra-state scale, was even worse when it came to inter-state endeavours. Acceptance came slowly and it took almost four years before all Divisions fully backed the venture.

Divisions bickered about the advertising and articles that did not reflect their particular modis operandi, at the same time as they were reluctant to 'dip their toe in the water' and provide material to publish.

Response, despite many detractors and publication problems from time to time, is still here after almost 30 years and ten Editors (each one apparently determined to introduce a different numbering system!). It has reported on major National ambulance 'events' and been the platform for many ambulance officers' first venture into reporting on a case study or research project. More importantly however Response has had a major influence on breaking down the barriers between the States and Territory's ambulance personnel.

Response has survived despite its knockers and without major assistance from the hierarchy of Ambulance Authorities. Had it not been for the influence of a couple of Councilors at the time, and the doggedness of the Victoria Division, in particular Barry Shadlow and Jim McGregor, it is difficult to know how long it would have taken Council to progress the idea.

\section{Les Hotchin}


The history of the magazine Response began as a result of the formation of The Institute of Ambulance Officers in Australia. The first recorded meeting of individuals to discuss the establishment of an Australian Institute of Ambulance Officers was conducted in Melbourne, Victoria, Australia in the Boardroom at the Windsor Hotel on Sunday $20^{\text {th }}$ June $1971 .{ }^{1}$

Mr. Laurie Shea, the Vice Chairman of the Ambulance Commission of Tasmania, convened the meeting "as it seemed apparent that there was a need for a body to bring together ambulance officers in Australia with a specific aim of increasing their professional competence and provide a forum for the exchange of technical information between leaders in allied disciplines and between ambulance leaders themselves". 2

Others attending this first meeting included Sir Douglas Fraser (Chairman of the Queensland Ambulance Transport Board), Mr. Maurice Kille (Chairman of the New South Wales Ambulance Transport Services Board), Mr. Bill Kelly (Secretary of the New South Wales Ambulance Transport Services Board), Mr. Alan Cumming (Superintendent/Secretary of Geelong and District Ambulance Service), Reverend Mr. James Martin (an Executive member of the Victorian Services Association) and Mr. Jock Berry (Director of Ambulance Training in Victoria). These people were selected for their long and active interest but did not officially represent the Authorities with whom they were associated.

At the meeting Mr. Alan Cumming referred to a Road Trauma Seminar held in 1969 conducted by the Royal Australasian College of Surgeons where it was made very clear "that the greatest improvement in return for invested efforts in the care of accident victims was at the roadside". 3 Mr. Cumming who had recently visited Ambulance Services in the United Kingdom went on to state "if senior officers in the Ambulance Services are to lead such on-road officers adequately, these senior officers should have technical abilities beyond those they lead. Many other disciplines have faced similar needs and found a good answer in the formation of a professional body which works to improve the abilities of its members by - setting a high standard of qualification for membership and - keeping members informed by publications, lectures and demonstrations of advances in their field".

Mr. Cumming reported that in the United Kingdom an Ambulance Institute had been founded and adopted with considerable success. He also promoted that such an Institute be established in Australia.

The meeting resolved that the concept of an Ambulance Institute be prepared and submitted to each State ambulance authority along with the following documents, a) a general proposal to form an Ambulance Institute in Australia, b) a broad description of a structure, c) a draft constitution and d) a proposed syllabus for courses and entrance examinations.

The next meeting took place at the Ambulance Officers Training Centre in Melbourne, Victoria on Saturday $22^{\text {nd }}$ January $1972 .{ }^{4}$ This meeting was poorly attended. At the meeting Mr. Ferrier the chairman of the Australian Ambulance Service Authorities Conference complained about the 
restricted number of States represented. The meeting resolved that all the ambulance authorities throughout Australia be urged to actively participate in the future. It was also agreed that ambulance authorities from all States and Territories be invited to attend another meeting in 12 weeks.

The next meeting was held in Melbourne on Saturday $15^{\text {th }}$ April 1972. ${ }^{5}$ At this meeting after considerable discussion and amendment, it was moved by Mr. Alan Cumming and seconded by Mr. Laurie Shea that set by-laws be adopted by this panel.

It was also resolved that the Institute of Ambulance Officers (Australia) be formed and that the Ambulance Authorities throughout the Commonwealth be asked to nominate, to the secretary of this investigating panel, Councilors in accordance with the interim by-laws to form the first Council of the Institute.

Subsequently the persons so nominated by the States and Territories Ambulance Authorities met in Melbourne on Friday $25^{\text {th }}$ August 1972 and adopted the draft by-laws. ${ }^{6}$ This led to a meeting the following day, on Saturday $26^{\text {th }}$ August, where it was moved Mr. William Kelly and seconded Mr. Laurie Shea - "that this meeting which consists of nominees of the Australian Ambulance Authorities of the Commonwealth of Australia for the purpose of forming the first Council of the Institute of Ambulance Officers (Australia) in accordance with the draft by-laws presented to the meeting by Sir Douglas Fraser on the $25^{\text {th }}$ August, $1972 \ldots$ now sit as the First Council of the Institute in accordance with these By-laws". 7

The Institutes' Council was thus founded and became established. A meeting of the executive committee of Council was held on $14^{\text {th }}$ April 1973 where it was agreed there was a need to formally launch the Institute. ${ }^{8}$ Thus the 'inaugural' meeting was held in Canberra on $30^{\text {th }}$ July 1973; this meeting was to become the first Annual General Meeting of the Institute of Ambulance Officers' (Australia). ${ }^{9}$

Gradually over the next two years Divisions of the Institute were established in each State and Territory. The Victoria Division, home to the "conception" of a magazine, held its first meeting prior to Council's inaugural meeting and by 1974 had a membership of $206{ }^{10}$ At the Victoria Division Annual General meeting conducted on $4^{\text {th }}$ of July 1974, a report from two members, Senior Station Officer Barry Shadlow and Station Officer Jim McGregor was tabled about the possibility of establishing a magazine. ${ }^{11}$ The meeting resolved accordingly and these two members were authorized to produce a magazine for a period of 12 months, with the first edition being supplied to all ambulance officers in Victoria as a means of boosting membership.

This heralded the birth of the magazine.

However, many challenges lay ahead.

The Victoria Division immediately established a Journal Administration Committee - initial members comprising Superintendent Reg Cheney (Chair), Mr. Tom Pammenter (secretary), Superintendent Laurie Wells, Senior Station Officer Les Hotchin, Station Officer Jim McGregor (Co-Editor) and Senior Station Officer Barry Shadlow (Co-Editor) - and the first edition of the magazine was published on the 1 st September $1974 .^{12}$ 
The first edition was called "The Journal of the Institute of Ambulance Officers (Australia) Victorian Division" and the editorial was titled "Foundations of Professionalism" with articles drawn mainly from official transcripts of addresses delivered at the official launch of the Institute of Ambulance Officers (Australia) on $30^{\text {th }}$ July $1973 .{ }^{13}$

The following medical specialists agreed to be appointed as the Journals Honorary Medical Consultants and Advisers - Dr David Burke, Director of Spinal Unit Austin Hospital, Melbourne Mr. Grayton Brown Deputy Chairman Road Traffic and Safety Authority Victoria, Mr. Julian Heinze Honorary Ophthalmic Surgeon Royal Victorian Eye and Ear Hospital, Melbourne, Dr David Hunt, Deputy Director Department of Cardiology Royal Melbourne Hospital, Mr. Julian Keogh, Assistant Surgeon Burns Unit Alfred Hospital Melbourne, Dr David Komesaroff Research Fellow Department of Surgery University of Melbourne \& Specialist Anaesthetist Royal Women's and Sandringham Hospitals, Melbourne, Professor Bernard Mc O'Brien, Plastic Surgery Department, St Vincent's Hospital Melbourne, Kannzian Professor of Plastic Surgery New York University Medical Centre USA \& Hunterian Professor of Royal college of Surgeons of England, Dr john Pedrotti, General Practioner \& Medical co-ordinator for The Journal of the Institute of Ambulance Officers (Australia). ${ }^{14}$

These eminent medical specialists played an important early role in providing the journal with medical oversight and approval. Institute leaders and members were pleased with their involvement and they are owed a considerable debt for the support.

In an attempt to develop the current Victoria based Journal towards a National Journal, in 1974 Mr. Alan Cumming, a National Councilor from Victoria, encouraged other States and Territories to support the Journal by subscribing. ${ }^{15}$ Queensland actively pledged their support for the Journal, whilst New South Wales was less supportive and guarded.

The second edition of the Journal, labeled "Autumn 1975", was distributed to all Divisions in the following 3 months. Accompanying the Journal was a letter from the National Secretary, Mr Jock Berry, advising that "Although it was planned and reported that the first edition of the journal would be produced cost free, considerable difficulty was experienced in collecting advertising fees from some advertisers and to date a substantial loss has been recorded. It may be that your Division would be prepared to subsidize purchases by your members to the extent of, say 50 cents, thus making the cost to the members more acceptable. Personally, I believe the Journal to be good quality and worth having... unless the circulation can be held at a reasonable level, the Journal will founder - which would be a great pity". ${ }^{16}$

In February 1976 the Secretary of Victoria Division, Mr Tom Pammenter wrote to the Secretary of Council, Mr Jock Berry, requesting Council consider forming a National Journal committee. ${ }^{17}$ In June of the same year the Victoria Division again contacted Council outlining an editorial policy and reporting on the financial position, highlighting that the Journal was "barely solvent". ${ }^{18}$

In the third edition, published in May 1976, the Editor Barry Shadlow noted that Queensland Division had now accepted the Journal as its official periodical. ${ }^{19}$ He also reported that Jim McGreggor, the initial co-editor of the Journal had notified him of his desire to leave the journal sub-committee. Barry went on the say "Mr. Jim McGreggor was responsible for the concept of a 
national Journal becoming a reality. Jim believed for many years that a national publication for ambulance officers was an important communication between ambulance officers and would help overcome the parochial state barriers that existed. Over the years his enthusiasm and drive never waned. When the Victoria Division was formed, he proved, by words and actions that his concept was sound, practical and possible. He worked untiringly as the advertising administrator for the journal and it was through his efforts in this capacity that enough financial support was gained to publish the first three editions".

On $29^{\text {th }}$ May 1976 Victoria Division proposed that all Divisions of the Institute become officially involved in the journal. ${ }^{20}$ Later that year, on the insistence of National Council, a National Editorial panel was formed comprising of Messers Alan Pitt, Malcolm McDonald and B Moore from Queensland, Mr Tony Heslin from New South Wales, and Mr Ken Maxworthy from the Australian Capital Territory. ${ }^{21}$

The fourth edition, labeled 'Autumn 1977" appeared late in that year. This was to be the last under Barry Shadlow as Editor. During his time as Editor, the Journal moved from an idea into reality and was starting to develop into an important part of the ambulance landscape, not only in Victoria but interstate.

About this time Mr Rod Coffey from the Victoria Division presented a paper to Council recommending a "formalization and rationalization of the Journal". 22 What this proposed was that the Journal take a different direction as a professional National Journal.

In August 1978, with new Editor Mr Terry Lee, the first "National" Edition (Journal) was published under the rebadged name of "Response" as the "Official Journal of The Australian Institute of Ambulance Officers (Australia)'. ${ }^{23}$ This was not a good start to a new journal, because the title was clearly incorrect, as the Institute was not the Australian Institute of Ambulance Officers, but the Institute of Ambulance Officers (Australia). This unfortunate error set Response up for a rocky start and invited considerable criticism and lack of confidence from some National Councilors and Divisions.

In this edition the National President, Mr Maurice Kille, contributed the lead article where he recognized and thanked the founders from Victoria for the initiative of developing the original magazine that has now progressed into a National Journal. ${ }^{24}$

Also in this edition Mr Jock Berry from Victoria wrote an article commenting on the progress of the Institute, including the slow progress towards uniting all ambulance

officers in the Commonwealth and recognition by all the Royal Colleges in the health field of the Institute as "the prime source of reference about ambulance matters". ${ }^{25}$

It was also at this time that the numbering system underwent a change; the first 4 editions of the magazine were numbered Vol. 1, No.1. through to Vol. 1, No. 4 and the first publication under the 'Response' banner was numbered Vol.1, No.1! Over time the numbering system underwent further alterations with current editions giving readers no clue as to the number of years the magazine has been in print. 
Later in 1978 it was reported that "Response" was floundering through lack of support; National Council was constantly urging all Divisions to provide material that could be incorporated into the journal. There was also some concern over the lack of editorial policy.

In 1979 the Journal was referred to in the National Council minutes as "Response" for the first time. ${ }^{26}$ It was also reported in Response of the progress with the course for elevation from Associate Member status to Member - this referred to a seminar conducted at Monash University in 1974 that had laid down the groundwork for an ambulance officer's course, and that the Victoria Ambulance Authority had now adopted this course at TAFE Certificate Level. ${ }^{27}$

In December 1979 Mr. Rod Coffey (a member of the Editorial panel and interim Editor), at the behest of Council convened a meeting with the purpose of developing an Editorial Policy and Editorial Rules. ${ }^{28}$ The subsequent proposal elicited some disquiet from Council members about the level of editorial freedom and independence proposed. However, eventually an 'Editorial Policy and Rules' were accepted. ${ }^{29}$

This change in ambulance officer training in Victoria heralded the first major shift from first aid based training of ambulance officer into health science education. This development in less than a decade from the establishment of the Institute was as a result of the vision, drive and insight of the founding fathers of the Institute. Response was the main vehicle for articles to be published and information disseminated to encourage ambulance officers and others to develop the confidence to strive and embrace new knowledge, skills and technologies.

This was clearly evident in 1980 when a thoughtful and challenging paper was published by Mr. Jock Berry relating to ambulance service titled "A Non-Academic Profession". ${ }^{30}$ Also published was a report about the first National Ambulance Competitions that were conducted at the Driver Education Centre in Shepparton Victoria on $11^{\text {th }}$ November 1979.

In 1981 it was reported to a Council meeting that there was major disagreement between the Editor of Response and National Council. ${ }^{31}$ This involved concern by Council about the editorial direction and control. Because this disagreement was not resolved, Council intervened and appointed Mr. Tony Heslin as provisional National Editor. ${ }^{32}$

Editorial problems continued to be reported for the following twelve months and Response continued to take up a lot of Council meetings' business time.

In 1982 Response published an issue (number 18) titled “An Anniversary Edition”. This was about ten years since the formation of the Institute. Unfortunately the Edition was overshadowed by a mistake, the front cover was incorrectly labeled as Edition 16,

October 1983. ${ }^{33}$ Apart from the disappointment felt by the Editorial Panel and Council at the time, Response had survived and grown from the first Edition of a meager 12 pages locally distributed into a 50 page nationally distributed Journal.

Over the period of 1983 to 1990 there were four National Editors of the Journal. On average four editions a year were published. However, there continued to be considerable pressure on Divisional Editors and the National Editor to keep Response going. This was due to the lack of quality articles from ambulance officers, balancing the number of articles with advertisements, 
managing publishers and publishing deadlines. These constant pressures took their toll both on individuals and at times the quality of the Journal. During the mid 1980s and 1990s the emergence of other ambulance and emergency journals created competition for the ambulance market and this coincided with an Institute down-turn in membership. Some in the ambulance industry were challenging the relevance of Response and many felt they could see where the journal needed to be improved but were unable to implement the changes required to ensure the journal's relevance.

In an attempt to get local ambulance input into the journal, each Division appointed a Divisional Editor to encourage articles, report on local activities, and manage the distribution locally. Each Divisional Editor was also appointed to the National Editorial Panel.

In 1989 Mr. John Hall was the New South Wales Divisional Editor, and in 1992 took over as the National Editor. ${ }^{34}$ John remained the National Editor for the next ten years. Under his stewardship the quality of articles improved to better reflect the modern ambulance paramedic. During that last decade of the twentieth century, the changes in ambulance training/education, management and clinical practice changed dramatically and Response battled to keep contemporary and relevant to the ambulance readership and the Institutes' membership.

\section{Editors}

Response has had ten Editors since it's inception, with John Hall from NSW recently retiring from this position after ten years.

$\begin{array}{lll}1974 & \text { Barry Shadlow } & \text { VIC } \\ 1978 & \text { Terry Lee } & \text { VIC } \\ 1979 & \text { Rod Coffey } & \text { VIC } \\ 1980 & \text { Wayne Jenkins } & \text { VIC } \\ 1981 & \text { Tony Heslin } & \text { NSW } \\ 1986 & \text { Steve Burns } & \text { QLD } \\ 1988 & \text { Andrew O'Brien } & \text { TAS } \\ 1989 & \text { Dennis Rogan } & \text { NSW } \\ 1992 & \text { John Hall } & \text { NSW } \\ 2002 & \text { Margaret Bertling } & \text { WA }\end{array}$

John Hall the longest serving National Editor of Response gives us a glimpse of his editorial perspective and what Response represents.

"My interest in Response commenced in 1989 when each State Branch had an editor. I became the NSW Divisional Editor under the National Editor Dennis Rogan. My interest increased when I attended a National Council meeting in Tasmania as the proxy for the National Editor. In 1992 I was approached to be the National Editor as Dennis Rogan had stood down from this position. I considered that as the National Editor I could influence the direction of Response over the next 2 years and give ambulance officers a chance to publish the projects they were involved in. Research by ambulance officers was almost non-existent at this time. . 
During my ten years as editor I tried to publish a Journal that reflected the current Australian ambulance practice through those years. During this time we have witnessed the expansion of Advanced Life Support throughout the Ambulance Services. The distribution of defibrillators throughout the systems has also been prominent. I published case studies and articles that reflected our operations. Sometimes these were controversial and created a great deal of debate. My main aim was to publish articles that would interest our members.

Some of the highs and lows included canceling the contract of two publishers and having to find replacements. I often had trouble finding enough suitable articles for each edition and acting as Editor, Managing Director and the Editorial Panel sometimes took its toll. The upside was that I received a great deal of satisfaction from seeing each edition being read at ambulance stations. The positive feedback I received and the support of my colleagues in the Institute and now the Australian College of Ambulance Professionals is the reason I survived for ten years. I have worked for four Presidents and each has provided supported to the Response Journal and the Editor. During my period as Editor, the concept of having a peer reviewed Journal was raised on several occasions. It was debated and then rejected by the Directors due to the fact that we always had an inconsistent supply of articles and it was felt that this might have excluded many articles that were subsequently published, e.g., case studies etc.

With the College now embarking on a new direction with respect to publications and providing dedicated platforms for our member's varied expressions, Response will continue to progress with a new editor and a new look.

I encourage each member to become involved with this new concept and contribute as you see fit to either - or both - "Response" and the electronic journal, the "Journal of Emergency Primary Health Care".

\section{References:}

1. A meeting to discuss the establishing of an Australian Institute of Ambulance Officers' - Minutes, $20^{\text {th }}$ June 1971.

2. A meeting to discuss the establishing of an Australian Institute of Ambulance Officers' - Minutes, $20^{\text {th }}$ June 1971.

3. A meeting to discuss the establishing of an Australian Institute of Ambulance Officers' - Minutes, $20^{\text {th }}$ June 1971.

4. Second meeting of the Panel to investigate the foundation of the Institute of Ambulance Officers' (Australia) Minutes, 22 $2^{\text {nd }}$ January 1972.

5. Third meeting of the Panel to investigate the foundation of the Institute of Ambulance Officers' (Australia)- Minutes, $15^{\text {th }}$ April 1972.

6. Meeting of Council Nominees of the Institute of Ambulance Officers' (Australia) - Minutes, $25^{\text {th }}$ August 1972.

7. Minutes, $26^{\text {th }}$ August 1972.

8. First meeting of Executive of Council of the Institute of Ambulance Officers' (Australia) Minutes, $14^{\text {th }}$ April 1973.

9. First Annual General Meeting of the Institute of Ambulance Officers' (Australia) - Minutes, $30^{\text {th }}$ July 1973.

10. Institute of Ambulance Officers' (Australia) Victoria Division - Minutes of Inaugural Meeting $8^{\text {th }}$ March 1973. 
11. Institute of Ambulance Officers' (Australia) Victoria Division - Minutes of meeting, $4^{\text {th }}$ July 1974.

12. Journal of the Institute of Ambulance Officers' (Australia) Victorian Division - Vol 1 No 1 September 1974.

13. Journal of the Institute of Ambulance Officers' (Australia) Victorian Division - Vol 1 No 1 September 1974.

14. Journal of the Institute of Ambulance Officers' (Australia) Victorian Division - Vol 1 No 1 September 1974.

15. Institute of Ambulance Officers' (Australia) - Minutes, AGM, $8^{\text {th }}$ October 1974.

16. Letter from Jock Berry, National Secretary, to Divisions $-25^{\text {th }}$ July 1975.

17. Letter from Tom Pammenter, Secretary Victoria Division, to National Secretary $-19^{\text {th }}$ February 1976.

18. Letter from Tom Pammenter, Secretary Victoria Division, to National Secretary $-22^{\text {nd }}$ June 1976.

19. Journal of the Institute of Ambulance Officers' (Australia) Victoria \& Queensland Divisions Vol 1 No 3 May 1976.

20. Institute of Ambulance Officers' (Australia) Victoria Division - Minutes of meeting, $29^{\text {th }}$ May 1976.

21. Institute of Ambulance Officers' (Australia) - Minutes of Council meeting, $9^{\text {th }}$ October 1976.

22. Submission to Council - Rod Coffey, $26^{\text {th }}$ August 1977.

23. Vol 1 No 1 "Response" - August 1978.

24. Vol 1 No 1 "Response" - August 1978.

25. Vol 1 No 1 "Response" - August 1978.

26. Institute of Ambulance Officers' (Australia) - Minutes of Council meeting, $20^{\text {th }}$ January 1979.

27. Institute of Ambulance Officers' (Australia) - Minutes of Council meeting, $20^{\text {th }}$ January 1979.

28. Institute of Ambulance Officers' (Australia) - Minutes of Council meeting, $22^{\text {nd }}$ September 1979.

29. Institute of Ambulance Officers' (Australia) - Minutes of Council Executive meeting, $15^{\text {th }}$ March 1980.

30. Vol 3 No 2 "Response" - March 1980.

31. Institute of Ambulance Officers' (Australia) - Minutes of Council meeting, $21^{\text {st }}$ November 1981.

32. Institute of Ambulance Officers' (Australia) - Minutes of Council meeting, $21^{\text {st }}$ November 1981.

33. Issue No 19 - November 1983.

34. Vol 15, No 4 "Response" - December 1992.

This article was peer reviewed for the Journal of Emergency Primary Health Care Vol. 1 (1-2), 2003 